\title{
PENGARUH MEDIA KOKORU TERHADAP KEMAMPUAN MOTORIK HALUS ANAK KELOMPOK B DI TK MUSLIMAT NURUL HUDA KECAMATAN SEKARAN KABUPATEN LAMONGAN
}

\author{
Retno Dwi Astuti ${ }^{1}$ \\ Program Studi PIAUD, Fakultas Agama Islam, Universitas Islam Lamongan \\ J1. Veteran No. 53 A Lamongan 62213 \\ Telp. 0322-324706/085648933318 \\ e-mail : retnodwiastuti9@gmail.com
}

\author{
Anisa Yunita Sari \\ Program Studi Pendidikan Anak Usia Dini, Universitas Narotama \\ Jl. Arief Rachman Hakim 51, Sukolilo-Surabaya \\ Telp. (031) 594 - 6404, 599 - 5578/ 086708055651 \\ e-mail : anisa.yunita@narotama.ac.id
}

\begin{abstract}
Abstrak
Penelitian Quasi Experimental Design ini bertujuan untuk membuktikan apakah media kokoru berpengaruh terhadap kemampuan motorik halus anak kelompok B di TK Muslimat Nurul Huda. Populasi penelitian adalah anak kelompok B di TK Muslimat Nurul Huda dengan sampel 20 anak kelompok B1 dan 20 anak kelompok B2. Teknik pengumpulan data menggunakan metode observasi dan dokumentasi. Teknik analisis data penelitian ini menggunakan Mann Whitney $U$ test dengan rumus Uhitung<Utabel $(\alpha=0,05)$. Dari hasil pengolahan data maka diperoleh U Hitung=22 dan Utabel 114, hal ini menunjukkan bahwa Ho ditolak dan Ha diterima. Berdasarkan uraian diatas dapat disimpulkan bahwa media kokoru berpengaruh terhadap kemampuan motorik halus anak kelompok B di TK Muslimat Nurul Huda.
\end{abstract}

Kata kunci : Kemampuan Motorik Halus, Media Kokoru

\begin{abstract}
The purpose in This Quasi Experimental Design design research to prove whether kokoru media has an effect on the fine motor skills of group B children in TK Muslimat Nurul Huda. The study population were children B group of TK Muslimat Nurul Huda with sample of 20 children in group B1 and 20 children in group B2. Technique of collecting data using observation and documentation methods. Test data analysis using Mann Whitney U test with the formula Ucount $<$ Utable $(\alpha=0,05)$. From the data
\end{abstract}


processing then obtained Ucount $=22$ dan Utable 114, it indicated that Ho is rejected and Ha accepted. Based on the above test it can be concluded that kokoru media have an effect on the fine motor skills of group B children in TK Muslimat Nurul Huda.

Keywords: Fine motor skills, Kokoru Media

\section{PENDAHULUAN}

Anak adalah manusia kecil yang memiliki potensi yang masih harus dikembangkan. Anak memiliki karakteristik tertentu yang khas dan tidak sama dengan orang dewasa, anak selalu aktif, dinamis, antusias dan ingin tahu terhadap apa yang dilihat, didengar dan dirasakan. Anak tidak pernah berhenti bereksplorasi dan belajar. ${ }^{1}$ Anak bereksplorasi dan belajar dari lingkungan sekitar dimana anak dibesarkan. Dimulai dari lingkungan keluarga, orang tua atau pihak lain yang terdekat dengan anak, dan guru diberbagai lembaga pendidikan yang memberikan layanan pada anak usia dini serta masyarakat sekitar. Melalui pemberian rangsangan pendidikan dapat membantu anak mengembangkan dan menumbuhkan jasmani dan rohaninya untuk memasuki pendidikan lebih lanjut, yang diselenggarakan pada jalur formal, non-formal, dan informal.

Berdasarkan UU RI Nomor. 20 Tahun 2003 tentang Sistem Pendidikan Nasional Bab 1, Pasal 1, Butir 14 dinyatakan bahwa pendidikan anak usia dini adalah suatu upaya pembinaan yang ditunjukkan kepada anak-anak sejak lahir sampai dengan usia 6 tahun yang dilakukan melalui pemberian rangsangan pendidikan untuk membantu pertumbuhan dan perkembangan jasmani dan rohani agar anak memiliki kesiapan dalam memasuki pendidikan lebih lanjut. Ki Hajar dewantara merangkum semua potensi anak menjadi cipta, rasa, dan karsa.Teori multiple intelligencies (kecerdasan ganda) dari Gardner menyatakan ada delapan tipe kecerdasan. ${ }^{2}$

Pada masa ini, terjadi hubungan antara sel-sel saraf, Kuantitas dan kualitas sambungan ini menentukan kecerdasan balita. Pada masa ini, perkembangan otak terjadi secara keseluruhan pada belahan otak kanan dan otak kiri. Otak kiri berhubungan dengan tangan, kaki, dan tubuh sebelah kanan, Otak kiri mengendalikan aktifitas yang bersifat teratur, berurutan, rinci, sistematis. Otak kanan berhubungan dengan tangan, kaki, dan tubuh sebelah kiri, Otak kanan mengendalikan aktivitas yang bersifat berpikir divergen (meluas), imajinasi, ide-ide, kreatifitas, emosi, music, intuisi, abstrak, bebas, simultan.Oleh karena itu untuk mengoptimalkan kecerdasan

\footnotetext{
${ }^{1}$ Sujiono, Yuliani Nurani, Konsep Dasar Pendidikan Anak Usia Dini (Jakarta:PT Indeks, 2009), 6

2 Trianto, Desain Pengembangan Pembelajaran Tematik Bagi Anak Usia Dini TK/RA Anak Usia Kelas Awal SD/MI. (Jakarta: Kencana, 2011), 13
} 
anak perlu dilakukan dengan melatih kedua tangan, kaki, mata, telinga kanan dan kiri secara seimbang setiap hari agar otak kiri dan kanan dapat berkembang secara optimal.

Berkaitan dengan itu, maka PAUD bertujuan membimbing dan mengembangkan potensi setiap anak agar aspek-aspek perkembangan dalam diri anak dapat berkembang secara optimal. Ada 6 aspek perkembangan anak usia dini menurut Peraturan Menteri Pendidikan dan Kebudayaan Republik Indonesia, Nomor 146 Tahun 2014 pasal 5 ayat 1, yaitu nilai agama dan moral, fisik-motorik, kognitif, bahasa, sosial emosional, dan seni ${ }^{3}$. Jika salah satu atau beberapa aspek tersebut bisa dikembangkan dengan baik, maka anak akan mampu mengolah bakat dan potensi yang terpendam dalam diri mereka dengan baik pula. Namun, akan lebih baik lagi jika semua aspek bisa berkembang secara menyeluruh dan seimbang. Salah satu aspek perkembangan yang menjadi fokus penelitian adalah aspek perkembangan motorik.

Perkembangan kemampuan motorik anak menurut Hurlock ${ }^{4}$ adalah perkembangan gerakan jasmaniah melalui kegiatan pusat saraf, urat saraf, dan otot yang terkoordinasi. Alasan utama mengapa di PAUD menjadi aspek atau ranah motorik adalah karena perkembangan motorik anak memiliki hubungan yang sangat signifikan dengan aspek-aspek yang lain, dan perkembangan anak secara dominan terlihat dari bagaimana kemampuan motoriknya berkembang. Hal ini sejalan dengan pendapat Samsudin ${ }^{5}$ yang menjelaskan bahwa perkembangan motorik merupakan perubahan baik fisik maupun psikis sesuai masa pertumbuhannya, sehingga sangat dipengaruhi oleh gizi, status kesehatan, dan perlakuan motorik yang sesuai dengan perkembangannya. Dengan kemampuan motorik yang bagus, seorang anak bisa dengan mudah dan lancar melakukan suatu kegiatan atau aktivitas yang bisa menunjang pertumbuhan dan perkembangannya. Salah satu keterampilan motorik yang membutuhkan kemampuan lebih rumit adalah keterampilan motorik halus.

Keterampilan motorik halus (fine motor skils) adalah keterampilan motorik yang melibatkan gerakan-gerakan yang diselaraskan seperti ketangkasan jari ${ }^{6}$. Oleh karena itu, gerakan motorik halus tidak terlalu membutuhkan tenaga, tetapi membutuhkan koordinasi yang cermat serta ketelitian.Keterampilan motorik halus lebih lama pencapaiannya dari pada kemampuan motorik kasar karena kemampuan motorik halus membutuhkan kemampuan yang lebih sulit. Misalnya,

${ }^{3}$ Depdikbud, Peraturan Menteri Pendidikan dan Kebudayaan Republik Indonesia Nomor 146 Tahun 2014 tentang kurikulum 2013 Pendidikan Anak Usia Dini (Jakarta: Depdikbud, 2014), 4

${ }^{4}$ Fakhruddin, Asef Umar, Sukses Menjadi Guru TK-PAUD (Jogjakarta: Bening, 2010), 115

${ }^{5}$ Samsudin, Pembelajaran Motorik di Taman Kanak-kanak (Jakarta: PT. Fajar Interpratama, 2008), 8

${ }^{6}$ Santrock, Jhon W, Masa Perkembangan Anak (Jakarta: Salemba Humanika, 2011), 214 
konsentrasi, kontrol, kehati-hatian, dan koordinasi otot-otot tubuh yang satu dengan yang lain. Oleh karena itu perlu adanya suatu kegiatan untuk mengasah dan mengembangkan kemampuan motorik halus anak. Selain itu, perlu adanya suatu media yang membantu agar otot halus pada tangan dapat bergerak, khususnya pada jari-jemari tangan anak.

Sehingga dalam hal ini adanya media sangat penting digunakan saat proses pembelajaran karena dapat membantu membangkitkan keinginan, motivasi dan merangsang anak untuk belajar.

Saat memilih media pembelajaran untuk anak, ada beberapa hal yang perlu diperhatikan.Salah satunya adalah menyesuaikan dengan tingkat pencapaian perkembangan motorik halus anak. Menurut Peraturan Menteri Pendidikan dan Kebudayaan Republik Indonesia Nomor 137 tentang standar nasional pendidikan anak usia dini, bahwa tingkat pencapaian perkembangan kemampuan motorik halus anak kelompok usia $5-\leq 6$ tahun sewajarnya mampu menggambar sesuai gagasannya, meniru bentuk, melakukan eksplorasi dengan berbagai media dan kegiatan, menggunakan alat tulis dan alat makan dengan benar, menggunting sesuai dengan pola, menempel gambar dengan tepat, serta mampu mengekspresikan diri melalui gerakan menggambar secara detail ${ }^{7}$.

Berdasarkan penjelasan diatas mengungkapkan bahwa perlu adanya suatu kegiatan untuk mengasah dan mengembangkan kemampuan motorik halus anak.Oleh karena itu peneliti menggunakan kegiatan dengan menggabungkan tiga indikator eksplorasi dengan berbagai media dan kegiatan, menggulung sesuai dengan bentuk, menggunting sesuai dengan pola, dan menempel dengan tepat.

Gerakan motorik halus melalui kegiatan menggulung, menggunting, dan menempel adalah gerakan yang melibatkan bagian-bagian tubuh tertentu yang dilakukan oleh otot-otot kecil. Kegiatan tersebut dapat mengembangkan kemampuan motorik halus anak, merangsang kreativitas, keterampilan dan imajinasi, mengasah mental geometrik, mengasah mental menjadi tekun, telaten dan sabar, serta sebagai media komunikasi antar guru dan peserta didik lainnya. Dalam hal ini, peneliti menggunakan media kokoru yang mencakup indikator kegiatan menggulung, menggunting, dan menempel. Ketiga indikator tersebut sesuai dengan target pencapaian kegiatan penerapan media kokoru untuk anak kelompok usia 5-6 tahun, yakni kelompok TK B.

\section{${ }^{7} \mathrm{Ibid}$}


Terkait dari hasil pengamatan atau observasi yang dilakukan peneliti, kegiatan yang dilakukan di TK adalah menggunting dengan menggunakan kertas Origami yang bertujuan untuk mengembangkan kemampuan dalam mengkoordinasikan mata dan tangan. Tangan, lengan dan jari semua gerak bersama di bawah perintah mata. Anak mengkoordinasikan mata dan tangan saat melakukan kegiatan menggunting menggunakan kertas origami menjadi berbagai macam bentuk geometri.

Penelitian ini dilakukan di TK Muslimat Nurul Huda karena belum pernah ada penelitian tentang Kemampuan Motorik Halus anak yang dilakukan di TK ini. Pemberian stimulasi yang tepat bagi anak sangat penting bagi membantu perkembangan anak. Tumbuh kembang anak dapat distimulasi dengan berbagai kegiatan yang anak peroleh saat di sekolah. Proses pembelajaran pada anak yang dapat memberikan rasa nyaman dan menyenangkan yaitu dengan memasukkan unsur permainan atau kegiatan dengan media yang menarik minat anak. Salah satu media yang dapat menarik minat anak yakni media kokoru. Corrugated paper dari bahasa latin yang berarti kokoru adalah kertas bergelombang yang memiliki beraneka ragam warna ${ }^{8}$.

Manfaat dari media kokoru sendiri adalah dapat digunakan untuk berbagai kreatifitas ketrampilan seperti dekorasi scarpbook, dekorasi majalah dinding sekolah, membuat kartu, pigura foto, hiasan, dll. Berkreasi sesuai imajinasi dengan membentuk kokoru menjadi binatang, boneka, mobil-mobilan, bangunan, dan kreasi lainnya ${ }^{9}$. Media kokoru memiliki kelebihan yaitu bisa melatih ketangkasan jari anak dalam menggunting, dengan bentuk yang bergelombang membuat anak membutuhkan tenaga lebih untuk mengguntingnya sehingga jari anak lebih kuat dalam memegang gunting dan menggunting. Selain ketangkasan tangan media kokoru juga dapat melatih kreatifitas anak, dengan beragam warna yang dimiliki anak bisa berkreasi sesuai dengan imajinasinya.

Sedangkan Tujuan dari penggunaan media kokoru adalah bisa mengembangkan kemampuan motorik anak, terutama motorik halus adalah dengan mengajak berkreasi.Selain memberikan perasaan senang, berkreasi juga dapat mengembangkan rasa percaya diri anak, dan melatih mereka mengembangkan imajinasinya. Jika anak memiliki kemampuan motorik yang baik, maka

\footnotetext{
${ }^{8}$ Suryani, Reno, Kerajinan Kokoru untuk Anak (Yogyakarta: PT Pustaka Ekonomi, 2014), 10

${ }^{9}$ Yuliana, Fun With Kokoru (Jakarta: Tiara Aksa, 2014), 2
} 
anak akan mampu beradaptasi dengan baik pula, sehingga anak akan mudah berteman dengan teman sebayanya (Suryani, 2014:7) ${ }^{10}$.

Berdasarkan uraian tersebut, diperlukan adanya pembelajaran yang dapat mempengaruhi keterampilan motorik halus anak. Salah satu media pembelajaran yang dapat mempengaruhi keterampilan motorik halus anak adalah media kokoru. Oleh karena itu peneliti mengambil judul

"Pengaruh Media Kokoru terhadap kemampuan motorik halus Anak Kelompok B di TK Muslimat Nurul Huda".

\section{METODE}

Penelitian dengan judul Pengaruh Media Kokoru terhadap kemampuan motorik halus anak kelompok B di TK Muslimat Nurul Huda ini menggunakan jenis penelitian kuantitatif karena data yang digunakan pada penelitian ini berupa angka dengan berbagai klasifikasi. Bentuk desain eksperimen dalam penelitian ini adalah quasi experimental design. Design ini mempunyai kelompok kontrol dan kelas eksperimen. Treatment ditujukan pada kelas eksperimen dan diharapkan treatment ini dapat memberikan hasil yang berbeda, artinya ada peningkatan yang lebih baik dari kelas kontrol. Hal ini dikarenakan pada kelas kontrol tidak diberikan treatment (perlakuan) mengenai apa yang sedang kita ujikan.

Populasi dalam penelitian ini adalah anak di TK Muslimat Nurul Huda. Sampel dalam penelitian ini adalah semua anak kelompok B di TK Muslimat Nurul Huda yang terdiri dari 2 kelas dengan jumlah sampel 20 anak perkelasnya, jadi ada 40 anak yang diteliti.

Teknik pengumpulan data yang digunakan dalam penelitian ini yaitu observasi (pengamatan) dan dokumetasi. Jenis observasi yang digunakan adalah observasi non partisipan, dimana peneliti tidak ikut terlibat dalam aktivitas pembelajaran. Sedangkan alat penilaian yang digunakan salah satunya dengan dokumen foto berupa video, foto kegiatan selama proses belajar anak kelompok B1 dan B2 di TK Muslimat Nurul Huda serta saat pre test, treatment menggunakan media kokoru, dan pada saat post test. Selain itu dokumentasi juga berupa Rencana Program Pembelajaran Harian (RPPH), lembar penilaian, lembar observasi penilaian anak, kisi-kisi instrument, data anak dan data sekolah. 
Sampel yang digunakan dalam penelitian ini adalah 20 anak dari kelas B1 dan 20 anak dari kelas B2. Data yang diperoleh berupa data ordinal karena data yang akan disajikan dalam bentuk rangking atau peringkat dengan menggunakan uji statistik Mann Whitney U test.

Analisis data Mann Whitney $U$ test digunakan untuk menguji hipotesis komparatif dua sampel independen dan datanya berbentuk ordinal dan dalam pelaksanaan pengujiannya hipotesis menggunakan Tabel penolong untuk pengujian U-test.

\section{HASIL DAN PEMBAHASAN}

Penelitian ini dilakukan dengan 3 tahapan, yaitu pre-test (sebelum perlakuan) treatment (perlakuan), dan post-test (sesudah perlakuan). Kegiatan pre-test dilakukan setelah menguji reliabilitas yang dilakukan di TK Muslimat Nurul Huda dan mendapatkan hasil dari uji reliabilitas tersebut. Kegiatan pre-test (sebelum perlakuan) data yang diambil untuk mengetahui seberapa jauh kemampuan anak menggunting kertas sesuai dengan pola, rapi, dan tepat pada garis potong, yang kedua adalah seberapa jauh kemampuan anak menggulung kertas sesuai dengan bentuk, padat, dan rapi. dan yang ketiga adalah seberapa jauh kemampuan anak menempel dengan lem secara merata, sesuai pada tempatnya, dan menggunakan lem secukupnya dengan waktu kegiatan \pm 90 menit waktu pelaksanaan.

Pada pretest yang dilakukan ini anak menggunting, menggulung, dan menempel menggunakan kertas origami dengan bentuk balon udara.Saat anak melakukan kegiatannya, pengamat dan penilai mengawasi anak selama melakukan kegiatan.

Kegiatan selanjutnya adalah melakukan kegiatan Treatment 1 menggunting dengan menggunakan kertas kokoru berikutnya yaitu anak istirahat untuk makan dan minum. Setelah istirahat, ketika kegiatan belum selesai maka dilanjutkan setelah istirahat. selanjtya guru mengajak anak untuk beres -beres dan bersiap untuk pulang. Guru melakukan tanya jawab mengenai kegiatan yang telah dilakukan. Setelah selesai anak siap berdo'a untuk pulang. Prosedur pelaksanaan treatmen 2 dan 3 sama halnya dengan treatment 1. Perbedaanya treletak pada kegiatannya yang treatment 2 (menggunting dan menggulung) sedangkan pada treatment 3 (menggunting, menggulung, dan menempel). Setelah kegiatan treatment selesai, dilakukan kegiatan post test, kegiatan yang dilakukan sama dengan kegiatan yang dilakukan sebelum diberi perlakuan (pretest) anak menggunting, menggulung, dan menempel menggunakan kertas origami dengan bentuk balon udara. 
Berdasarkan data yang diperoleh dari hasil observasi awal (pre-test) dan hasil observasi akhir (post-test) tentang pengaruh media kokoru terhadap kemampuan motorik halus anak kelompok B di TK Muslimat Nurul Huda yang terdidri dari 2 kelas, dan masing-masing kelas jumlahnya 20 anak, selanjutnya dianalisis dengan statistik nonparametrik menggunakan uji Mann Whitney U-test. Alasan menggunakan rumus Mann Whitney U-testyaitu untuk mencari perbedaan kemampuan motorik halus anak kelompok B di TK Muslimat Nurul Huda dalam hal kemampuan menggunting sebelum dan sesudah diberikan perlakuan menggunakan media kokoru. Uji Mann Whitney U-test dalam penelitian ini menggunakan tabel penolong U-tes:

Tabel 4.6

Tabel Penolong Untuk Pengujian Dengan U-Test

\begin{tabular}{|c|c|c|c|c|c|}
\hline Kel B1 & Produk & Peringkat & Kel B2 & Produk & Peringkat \\
\hline 1 & 2 & 17 & 1 & 1 & 6,5 \\
\hline 2 & 2 & 17 & 2 & 1 & 6,5 \\
\hline 3 & 4 & 33 & 3 & 1 & 6,5 \\
\hline 4 & 3 & 26 & 4 & 2 & 17 \\
\hline 5 & 2 & 17 & 5 & 1 & 6,5 \\
\hline 6 & 5 & 37 & 6 & 2 & 17 \\
\hline 7 & 3 & 26 & 7 & 3 & 26 \\
\hline 8 & 3 & 26 & 8 & 1 & 6,5 \\
\hline 9 & 6 & 39,5 & 9 & 3 & 26 \\
\hline 10 & 3 & 26 & 10 & 2 & 17 \\
\hline 11 & 3 & 26 & 11 & 2 & 17 \\
\hline 12 & 4 & 33 & 12 & 1 & 6,5 \\
\hline 13 & 6 & 39,5 & 13 & 1 & 6,5 \\
\hline 14 & 4 & 33 & 14 & 2 & 17 \\
\hline 15 & 3 & 26 & 15 & 1 & 6,5 \\
\hline 16 & 5 & 37 & 16 & 1 & 6,5 \\
\hline 17 & 4 & 33 & 17 & 2 & 17 \\
\hline 18 & 4 & 33 & 18 & 1 & 6,5 \\
\hline 19 & 5 & 37 & 19 & 1 & 6,5 \\
\hline 20 & 3 & 26 & 20 & 1 & 6,5 \\
\hline & & $\mathrm{R} 1=588$ & & & $\mathrm{R} 2=232$ \\
\hline
\end{tabular}

$$
\begin{aligned}
U_{1} & =n_{1} n_{2}+\frac{\left.n_{1\left(n_{1}\right.}+1\right)}{2}-R_{1} \\
& =20.20+\frac{20(20+1)}{2}-588 \\
& =22
\end{aligned}
$$

$$
\begin{aligned}
\mathrm{U}_{2} & =n_{1} n_{2}+\frac{n_{1\left(n_{1}+1\right)}}{2}-R_{2} \\
& =20.20+\frac{20(20+1)}{2}-232 \\
& =378
\end{aligned}
$$


Pada hasil perhitungan nilai kritis yang diperoleh menunjukan bahwa harga nilai $\mathrm{U}_{1}$ dari kelompok eksperimen lebih kecil dari kelompok kontrol yaitu $\mathrm{U}_{2}$.Melihat hasil analisis Mann Whitney U-Test yang menunjukkan bahwa penggunaan media kokoru dapat mempengaruhi kemampuan Motorik Halus Anak Kelompok B di TK Muslimat Nurul Huda. Hal tersebut dibuktikan dengan hasil perhitungan antara U Tabel dan U Hitung dimana U Tabel 114 sedangkan U Hitung 22, apabila U Hitung< Utabel, maka Ho ditolak dan Ha diterima. Sedangkan apabila U Hitung> Utabel, maka Ho diterima dan Ha ditolak. Dari analisis data maka diperoleh U Hitung< Utabel yakni $22<114$, sehingga Ho ditolak yaitu tidak adanya pengaruh media kokoru terhadap kemampuan motorik halus anak kelompok B di TK Muslimat Nurul Huda dan Ha diterima yaitu adanya pengaruh media kokoru terhadap kemampuan motorik halus anak kelompok B di TK Muslimat Nurul Huda.

\section{PENUTUP}

\section{Simpulan}

Berdasarkan hasil penelitian data rekapitulasi kelompok antara kelompok kontrol dan eksperimen membuktikan bahwa kelompok eksperimen yang mendapatkan perlakuan dengan menggunakan media kokoru mengalami peningkatan skor pada kemampuan motorik halus anak kelompok B dalam kegiatan menggunting, menggulung, dan menempel.

Berdasarkan analisis data yang telah dilakukan dengan uji U-test (Mann-whitney U-test) jumlah $\mathrm{N}_{1}=20$ dan $\mathrm{N}_{2}=20$ diperoleh harga $U$ Hitung $<$ Utabel yakni 22<114, sehingga Ho ditolak yaitu tidak adanya pengaruh media kokoru terhadap kemampuan motorik halus anak kelom B di TK Muslimat Nurul dan Ha diterima yaitu adanya pengaruh media kokoru terhadap kemampuan motorik halus anak kelompok B di TK Muslimat Nurul Huda.

Dengan demikian media kokoru berpengaruh terhadap kemampuan motorik halus anak kelompok B di TK Muslimat Nurul Huda.

\section{Saran}

Setelah dilakukan penelitian tentang pengaruh media kokoru terhadap kemampuan motorik halus anak kelompok B di TK Muslimat Nurul Huda dengan hasil adanya pengaruh media kokoru terhadap kemampuan motorik halus anak kelompok B di TK Muslimat Nurul Huda. Maka penelitian dapat mengemukakan saran sebagai berikut: 
1. Hendaknya guru dapat menambah variasi belajar mengajar dengan menggunakan media kokoru dengan berbagai variasi bentuk yang lain atau kegiatan lainnya yang dapat mengembangkan motorik halus anak karena aktivitas motorik halus anak pada usia dini sangat besar presentasinya.

2. Guru dapat menggunakan media kokoru tidak hanya sebagai mengembangkan kemampuan motorik halus anak namun juga dapat dikembangkan pada aspek lain (kognitif, bahasa, moral agama, dan sosial-emosional). Dengan media yang sama namun dibuat lebih menarik lagi sesuai dengan aspek perkembangan yang akan dikembangkan.

3. Peneliti dari media kokoru yang telah dilakukan ini dapat dikembangkan lagi pada penelitian yang lebih baik lagi khususnya pada bidang pengembangan motorik halus anak usia dini.

\section{Daftar Rujukan}

Depdikbud. 2014. Peraturan Menteri Pendidikan dan Kebudayaan Republik Indonesia Nomor 146 Tahun 2014 tentang kurikulum 2013 Pendidikan Anak Usia Dini. Jakarta: Depdikbud.

Depdikbud. 2014. Peraturan Menteri Pendidikan dan Kebudayaan Republik Indonesia Nomor 137 Tahun 2014 tentang Standar Nasional Pendidikan Anak Usia Dini. Jakarta: Depdikbud.

Fakhruddin, Asef Umar. 2010. Sukses Menjadi Guru TK-PAUD. Jogjakarta: Bening.

Samsudin.2008. Pembelajaran Motorik di Taman Kanak-kanak. Jakarta: PT. Fajar Interpratama.. Santrock, Jhon W. 2011. Masa Perkembangan Anak. Jakarta: Salemba Humanika.

Sujiono, Yuliani Nurani. 2009. Konsep Dasar Pendidikan Anak Usia Dini. Jakarta:PT Indeks.

Suryani, Reno. 2014. Kerajinan Kokoru untuk Anak. Yogyakarta: PT Pustaka Ekonomi.

Trianto. 2011. Desain Pengembangan Pembelajaran Tematik Bagi Anak Usia Dini TK/RA Anak Usia Kelas Awal SD/MI. Jakarta: Kencana.

Yuliana. 2014. Fun With Kokoru. Jakarta: Tiara Aksa 